\author{
JULIO ESTRADA
}

INSTITUTO DE INVESTIGACIONES ESTÉTICAS, UNAM

\title{
Pauline Oliveros (1932-2016)
}

En febrero de 2017 participamos varios músicos en Las raíces del momento, un homenaje a Pauline Oliveros organizado en Cuernavaca por la compositora y musicóloga Tania Rubio. Para mí fue una gratísima revelación constatar que la gran iconoclasta de la creación musical fuese tan reconocida, admirada y querida por decenas de jóvenes mexicanos, que le dedicaron con emoción y calidad una larga e intensa sesión para recodarla: un concierto acústico con Resonancias, dos improvisaciones dirigidas por Mariana Villanueva que enmarcaron, con su conjunto instrumental, una versión reciente de En Do de Terry Riley — amigo entre los primeros de Pauline—, una mesa de diálogo, moderada por Tania, con expertos en música digital en México - Manuel Rocha, Roberto Morales, Vicente Rojo, Rogelio Sosa y Antonio Russek-, quienes luego de un acto previo de Deep Listening, la escucha profunda de los jóvenes organizadores -Elías Xolocotzin, Galo González, Tito Quintana, Daniel Álvarez y Tania Rubio-, refrendaron la misma proposición de crear un acto en vivo, al improvisar cada uno en su equipo electrónico.

El programa de la celebración consignaba una declaración poética de Pauline Oliveros, que aquí traduzco:

Yo podría amar a mi escucha

Yo podría escuchar a mi escucha

Yo podría interpretar a mi escucha

Yo podría ser mi escucha. ${ }^{\mathrm{I}}$

* Texto recibido el 27 de noviembre de 20I8; aceptado el 9 de enero de 20I8, https//doi/Io.2220I/ iie.18703062e.2019.1I4.2673.

I. "I could love my listening / I could listen to my listening / I could perform my listening / I could be my listening", en Pauline Oliveros, programa Las raices del momento, homenaje a la compositora Pauline Oliveros, Sala Ponce, Cuernavaca, Morelos, México, 24 de febrero de 2017. 
Escuchar, amar o ser son, en la creadora musical estadounidense, una unidad indisoluble que remite a una acción simple: atender con el oído al mundo externo e interno, una forma de sabiduría esencial para el proceso creativo e interpretativo, algo que para muchos músicos pasa a un segundo o último plano al ceder el sitio tanto a la técnica como al sistema. Pierre Schaeffer, en su Tratado de los objetos sonoros, ${ }^{2}$ distingue cuatro momentos que describen la evolución del proceso auditivo —oír, escuchar, entender y comprender-, desde la acción sensorial refleja hasta la operación cognitiva que deja asimilar el sentido y el significado de una señal. En la música del siglo xx, la escucha comienza a adquirir relevancia cuando se está desprovisto de las herramientas instrumentales o de los métodos pedagógicos que antes parecían resolver el problema; con el impacto brutal de la primera y segunda guerras mundiales sobre la conducta social, comienza a considerarse la escucha como una actividad prioritaria - véase en el futurismo italiano y sus intonarumori al inicio de la segunda década, y la musique concrète en la cuarta, ambas llamadas de atención sobre lo insólito: escuchar ruido. Hoy podemos poner en duda la noción misma de ruido, por su implicación más peyorativa que estética, y también por la dificultad de nombrar lo diferente, aquello que sale del marco de referencia de nuestros valores de belleza - como ocurre de igual manera con los valores éticos, morales o religiosos- y no sabemos evaluar, mejor aún, entender y comprender.

En mi breve exposición que presenté en Cuernavaca recordaba, ante el público, cómo en un viaje de turismo a California en 1973 hice el trayecto de San Francisco a San Diego para conocer el Centro de Experimentación Musical (CME), cuya fundación y propuestas innovadoras en 1971 me llamaban la atención al estar en concordancia con la búsqueda transformadora de la música. Debía ser un fin de semana o acaso vacaciones porque no había casi gente. El Centro estaba instalado en varias cabañas rústicas con forma de medios cilindros que habían servido de residencia o de oficina a los Marines en La Jolla. Ahí tuve la gran sorpresa de encontrarme con Pauline Oliveros, cuyo nombre conocí primero por la revista Source de 197I — novedad editorial que recuerdo entre las afinidades iniciales que tuve con Conlon Nancarrow- donde leí con admiración "Algunas observaciones sobre el sonido", 3 texto que me resultó difícil no comparar con Aus den sieben Tagen, librito que el propio Stockhau-

2. Pierre Schaeffer, Traité des Objets musicaux, essai interdisciplines (París: Éditions du Seuil, 1966).

3. Pauline Oliveros, "Some Sound Observations", Source, Music of the Avant Garde, núm. 3 (1971): 77-79. 
sen lanzaba de regalo sobre la gran mesa de clase con aire de croupier a quienes estudiábamos con él en Colonia en 1968. Mientras que el alemán escribía sobre los ritmos del cuerpo, la mente o el universo como fuentes de inspiración para vincular la escucha de sus intérpretes en una imaginación colectiva, Pauline podía escribir sobre los objetos del mundo común y corriente, dentro de la sencillez de un artículo concebido a la manera de una antropóloga que hace "observaciones sonoras" — mi traducción:

A la vez que estoy aquí sentada tratando de componer un artículo para Source, mi mente se adhiere a mis propios sonidos y a los de mi entorno. A lo lejos, una excavadora se come una ladera mientras que su motor es una cascada de armónicos que define el espacio entre ella y el rock and roll del radio que suena en la habitación contigua. Sonidos de pájaros, insectos, voces de niños y el susurro de los árboles salpican este espacio. ${ }^{4}$

Si las voces infantiles se enlazan a El canto de los adolescentes — Gesang der Jünglinge — de Stockhausen, ambos autores ingresaban al universo de la creación musical mediante la palabra para mostrar una afortunada analogía que abstrae el código escrito, en contraste con la que encierra a la música en su reserva para los iniciados. A diferencia de la música hecha de alturas provenientes de escalas y ordenada con criterios de melodía, armonía y contrapunto, y registrada con conjuntos de notas, el oído puede acceder a otra música tan sólo con dar a la mente la libertad de situarse en una distinta condición; por ejemplo, la de observar el sonar de la naturaleza, cuyo esplendor sensibiliza a la persona de cualquier condición o, por ejemplo, la de escuchar al imaginario, esas dos perspectivas que adoptan una y otro creadores. En cuanto al impacto de esa doble búsqueda sobre otros, me encuentro entre quienes la asimilaron mediante breves textos para explorar el oído - "Imaginaria", "Solo para uno", "Cinco poemas y un cuento de primavera" - 5 o en un campo adicional, "Canto alado", 6 parte del proyecto

4. "As I sit here trying to compose an article, my mind adheres to the sounds of myself and my environment. In the distance a bulldozer is eating a hillside while its motor is a cascade of harmonics defining the space between it and the rock and roll radio playing in the next room. Sounds of birds, insects, children's voices and the rustling of trees fleck this space", en Oliveros, "Some Sound Observations", 78.

5. Julio Estrada, "Cinco poemas y un cuento de primavera", Universidad de México 33, núm. II (1979): I9 y 20.

6. Julio Estrada, "Canto alado", Pauta I, núm. I (I982): 7I-72. 
de crear una literatura auditiva con Música ficción, tema que poco tiempo después me condujo a postular a una beca como escritor y, por ello, a conocer en persona a Juan Rulfo hacia 1975 y, algo más tarde, a adentrarme en el estudio de su obra, precursora en estos asuntos. ${ }^{7}$

Cuando llegué a La Jolla, Pauline estaba acompañada por Gerald Shapiro, un músico estadounidense que la visitaba y a quien conocí en París como parte del grupo de alumnos privados que estudiábamos con Nadia Boulanger; él, practicante de Webern, me había explicado el serialismo integral, una vacuna que me duró un par de meses y luego de la cual regresé a gozar de nuevo de la música. Gerald y yo nos miramos con cierto pasmo considerando la rareza de nuestra visita a la compositora a sabiendas de lo formal de nuestras respectivas formaciones. A la alegría del reencuentro con Shapiro se añadía la posibilidad de encontrarme con Pauline, de quien tenía curiosidad de conocer más sus ideas. Con su inmediata y sencilla hospitalidad ella me integró a la experiencia de sentarnos los tres en el suelo para escuchar con atención sonidos de un equipo electrónico y cantar en concordancia con ello, los tres tomados de la mano a la manera de una meditación amistosa, algo que había practicado con Daniel Raguin y Bernard Leblanc en el trío de improvisación que formamos, el Néo-Néo, como reflexión creativa en el 68 parisino. Al poco tiempo se unió a nosotros el músico más influyente de la Universidad de California San Diego, Roger Reynolds, fundador del Centro para la Experimentación Musical, con quien continuamos cantando y conociendo tanto el para qué de aquello como el carácter inquisitivo de sus preguntas inteligentes. Creo que Pauline nunca mencionó el título de alguna obra para esta experiencia, pero es probable que se tratara de una parte de Tuning Meditations - meditaciones de afinación - para voz y audiencia amplificada (I97I), o quizá se tratara de sus "piezas de escucha profunda", Deep Listening Pieces, is piezas con eventual participación del público (1971-1990).

Al concluir aquella sesión espontánea y demostrativa Reynolds se quedó dentro y los tres salimos de la cabaña; Gerald se fue directo al aeropuerto para emprender el viaje de regreso al Este, mientras que yo disfruté un momento, que aún perdura, charlando a solas con Pauline en los jardines; recuerdo que me confirmó el origen portugués de su apellido o que me recomendó a mi vuelta a San Francisco ir a comer al barrio chino y aprovechar para escuchar al grupo

7. Julio Estrada, El sonido en Rulfo: el ruido ese, prólogo de Akira Sugiyama (México: Universidad Nacional Autónoma de México-Instituto de Investigaciones Estéticas, 2008). 
de ópera china que en aquel entonces se presentaba en la ciudad y que ella tanto había admirado. Su candidez y franqueza eran notables; con trenza o pelo suelto, unos pantalones vaqueros y una camisa a cuadros a la usanza llanera, la joven compositora de 38 ańos revelaba que estaba escribiendo, por primera vez, un cuarteto de cuerdas, y que no tenía aún las ideas claras porque era inexperta para componer con una formación similar. Quizá se refería a una obra hecha de tonos prolongados que forman gradualmente sonoridades distintas, 70 Chords for Terry, ${ }^{8}$ dedicada a Riley, gran amigo con quien ella como acordeonista estrenó en 1964 En Do - otra confluencia musical en nuestra grata conversación-, que estrenamos en México en 1970 con el Conjunto Pro Música Nueva, siguiendo la recomendación que en 1969 me hizo el ingeniero Javier Barrios Sierra, rector que destacó por su intensa afición musical.

Antes de irme al aeropuerto, Pauline me pidió esperar un instante, volvió al espacio en el que habíamos estado y regresó con una simpática postal que guardo con carińo: ella, fotografiada entre unos arbustos en los que se distingue también a su izquierda un busto de Beethoven, y al pie, la leyenda: "Beethoven was a lesbian". Aquel texto arriba citado sobre la escucha declaraba ya con claridad su postura respecto a sexualidad y música: "Pauline Oliveros es un ser humano con dos piernas, una mujer, lesbiana, música, compositora, entre otras cosas que contribuyen a su identidad" (fig. I). ${ }^{9}$

De aquel encuentro franco y humano surgió una amistad duradera hasta sus últimos días. En 1978 vino a México invitada al Seminario de Investigación en Creación Musical y Futuro que organicé en la UnAM, donde dio una conferencia acompañada de su amiga Nina Montano, quien se recostó estoica en la mesa del podio a la vez que Pauline le aplicaba acupuntura en las extremidades y leía su texto. En la serie de conciertos nocturnos se presentó una obra suya para dos trompetas, con la cual incitó a todos a participar escuchando y cantando a la vez, gesto de su espontaneidad característica que propició en la audiencia una nueva actitud hacia la audición, per se.

En la fiesta privada que se organizó para cerrar con alegría aquel encuentro, logré provocar un cálido choque humano y musical, no sin pulla humorística: hacer que Pauline bailase a dúo una cumbia con su perfecta antípoda,

8. Pauline Oliveros, 70 Chords for Terry, consultado el II de marzo de 2019, en https://www. youtube.com/watch?v=j9x7IYwkIrA (escuchar a partir del instante 20:49 al 28:45).

9. "Pauline Oliveros is a two-legged human being, a female, lesbian, musician, composer, among other things which contribute to her identity", en Pauline Oliveros, "Some Sound Observations", 77. 
el impasible Iannis Xenakis, también invitado a presentar sus ideas y obras en aquellos días en los que acababa de concluir su proyecto de dibujo y conversión musical digital, la UPIC. Fue aquel un microinstante de historia musical danzada por dos figuras que defendían, una, el indeterminismo mediante instrucciones verbales muy abiertas, y otra, por una escritura que proyectaba su captura al producirlo por medios estadísticos.

En 1982, como profesor visitante del Departamento de Música de UCSD, volví a encontrarme con Pauline, que vino a buscarnos a Velia y a mí para ir a desayunar a su casa de Encinitas, al norte de La Jolla. Observé cómo, con los años, Pauline había dejado crecer su escaso bigote, afirmación que acentuaban tanto sus overoles como la tosca camioneta de carga que conducía, todo en contraste con la dulce y sutil persona que era. Es triste e inaceptable que Pauline tuviese que dejar en 198I su posición como profesora de composición en La Jolla, presionada hasta el borde por una turbia censura que hoy habría generado un escándalo monumental: el rechazo a que fuese lesbiana y también pionera para expresarlo con libertad. Una persecución no menos deplorable ocurrió con el inventivo Harry Partch en la misma universidad, cuando tuvo que trasladarse con su colección de instrumentos a la sencilla Universidad de San Diego, más cerca de la frontera - alguna tenía que haber para los distintos-y más permisiva para el homosexual que era. Ambas experiencias recuerdan con dolor y vergüenza la desgracia mucho mayor que décadas antes vivió en el mismo estado de California Henry D. Cowell, nacido y residente de Menlo Park, vecino de la Universidad de Stanford, a quien por sus convicciones políticas de izquierda le castigaron con cargos sobre su homosexualidad en la cárcel de San Quintín. El contraste que presentan estos tres casos —o cuatro, de añadir al exiliado en México, Conlon Nancarrow - con la generosa tersura con la que John Cage, californiano y exalumno de Cowell, fue tradicionalmente tratado por los servicios culturales de las embajadas de su país en los frecuentes viajes que realizaba al extranjero, es un asunto que dejo suspendido en el aire para su exploración por los interesados en la historia del tema planteado por Pauline, sexualidad y música, o por el de ambos asuntos con la política.

Aunque nada impidió la buena fama de Pauline como mujer, artista y maestra, lamento que a causa de la distancia geográfica de su exilio universitario tuviésemos muchos de sus amigos menos encuentros con ella. A pesar de permanecer ella ajena al típico medio formal académico de los Estados Unidos, siempre tuve noticias de que continuaba formando a generaciones de jóvenes 


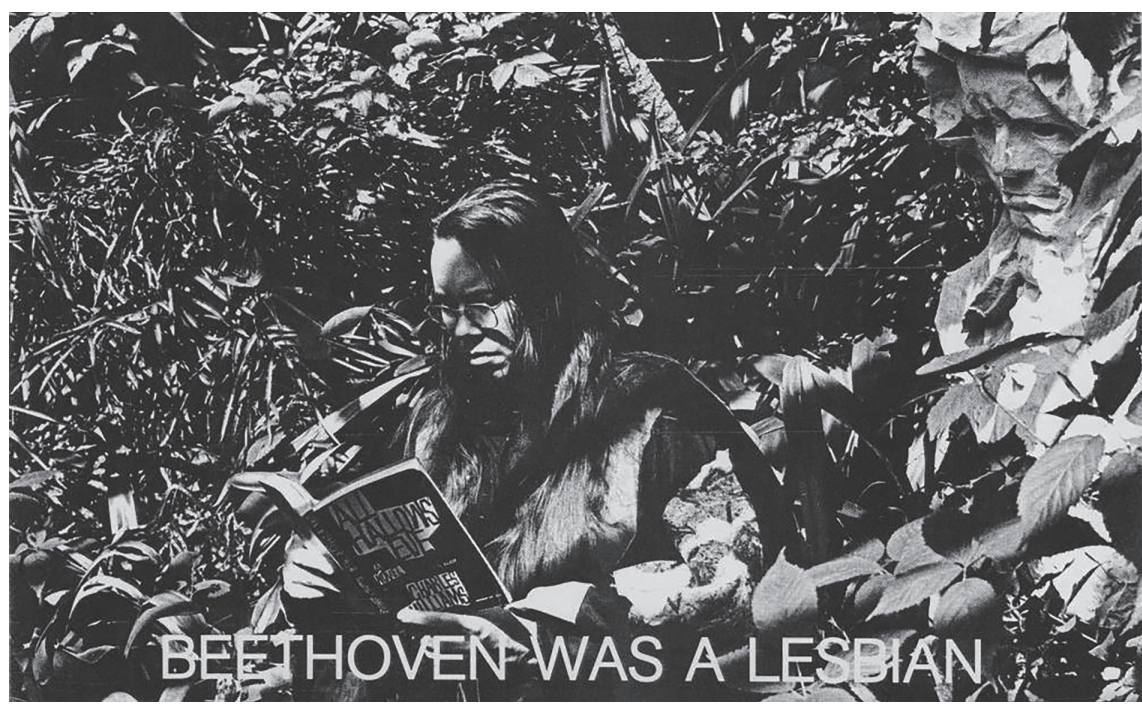

I. Fotografía del Post card Theater, por Alison Knowles y Pauline Oliveros. Siet original de las tarjetas postales publicadas en 1974 por Aenjai Graphics, Nueva York. Tomada de Wire https:// www.thewire.co.ule/in-writing/essays/pauline-oliveros-louise-gray.

músicos interesados en acercarse a sus clases individuales y colectivas en Nueva York. Ella podía saber de mí porque recomendaba con frecuencia a mis estudiantes a descubrir lo primordial de su enseñanza, tan sencilla como una revelación: saber escuchar para saber crear.

Da gusto reencontrar a Pauline aún hoy en redes como la de academia.edu, donde permanece en parte su legado escrito, como ocurre con el precioso mensaje que envía con proverbial sencillez en uno de sus textos:

Durante muchos años he conducido grupos orientados a la creación de música mediante la interacción sonora. Una de las formas más simples y efectivas es el Coro de escucha profunda. Personas de todas partes parecen necesitar hacer sonidos no verbales. Se realizan principalmente de manera inconsciente todos los días, aunque casi nunca de manera consciente y en grupo. La creación de sonidos no verbales es una forma de expresar emociones y explorar lo desconocido. Quienquiera que participe se siente liberado, lo que conlleva otras actividades a la vez que ayuda a activar la imaginación o simplemente a refrescar la mente. Hacer sonidos vocales 
sin restricciones es placentero. El entrenamiento no musical es necesario, pero a partir de ahí es posible alcanzar una experiencia musical. ${ }^{10}$

En los últimos años descubrí, por la red digital, que Pauline Oliveros aún estaba en Nueva York, ahora como profesora del Instituto Politécnico Rensselaer de Troy, seguramente un sitio más seguro y placentero para ella y su modo de vivir; me di a la tarea de buscar su teléfono y llamé a la oficina. Como siempre, asequible, tuve la fortuna de charlar con Pauline durante un buen momento, y si éste era acaso cercano en pocos meses a su fallecimiento, no denotaba en su voz ningún padecer: se dijo que, sin más, murió estando dormida. El tema al centro de nuestra conversación fueron sus escritos en torno a la audición profunda, una idea musical que en el orden social sabía cómo compartir, y con la cual ofrecía su visión artística, metafísica también, que pedía partir de la meditación como la forma de aproximación al yo. Sin necesitar ponerse o estar de acuerdo en algo específico, no podía coincidir más con alguien entre los músicos porque, en lo que hace a mi cada vez más solitaria labor en el crear musical, ensayo en estos años escribir, más que música mediante notación o conversión de dibujos a partitura, imaginaciones que describo con palabras para nombrar la escucha, pero ésa es una historia que podré contar cuando concluya mi tarea. \$\$

Io. Véase https://www.academia.edu/I9937I/InteractiveMusic, consultado el II de marzo de 2019. 